\title{
Utilização agrícola de lodo industrial como fonte de zinco na cultura do crisântemo
}

\author{
Luciano F. Lopes; Antonio Carlos S. Costa; Pérsio Sandir D'Oliveira; Luciano G. Gil
}

UEM, Pós Graduação em Agronomia, Av. Colombo, 5790, 87020-900 Maringá-PR; E-mail: acscosta@uem.br

\begin{abstract}
RESUMO
A utilização de lodo industrial inorgânico em substratos comerciais ou como fonte de nutrientes, é prática bem recente. O lodo produzido pela indústria de galvanoplastia-zincagem apresenta elevados teores de nutrientes como $\mathrm{Zn}, \mathrm{Fe}$, e $\mathrm{Ca}$ que, dependendo das doses utilizadas em solos e substratos, podem causar toxidez às plantas. No presente experimento foi utilizado um substrato comercial onde foram adicionadas doses crescentes do lodo industrial de galvanoplastia-zincagem para o cultivo de crisântemo, variedade Rage, em cultivo protegido. As doses do lodo industrial utilizadas foram de 0,$0 ; 0,38 ; 0,75 ; 1,50 ; 3,0 ; 6,0 ; 9,0$ e $12,0 \mathrm{~g} \mathrm{~L}-1$ de substrato. Após 12 semanas de cultivo foram avaliadas as seguintes variáveis: $\mathrm{pH}$ e condutividade elétrica do substrato, teor de $\mathrm{Zn}$ na parte aérea da planta e no substrato, altura da planta (ALT), massa seca da parte aérea (MSPA), massa seca das inflorescências (MSF) e massa seca do sistema radicular (MSR). A adição do lodo industrial no substrato, na dose de $0,38 \mathrm{~g} \mathrm{~L}-1$, promoveu um pequeno incremento de ALT, MSPA e MSR. Este comportamento indica que o lodo industrial pode fornecer nutrientes à cultura. Nas doses superiores a $3 \mathrm{~g} \mathrm{~L}-1$ ocorreu acentuada queda da produção devido ao desbalanço nutricional associado à fitotoxidez de $\mathrm{Zn}$ e elevada condutividade elétrica do substrato.
\end{abstract}

Palavras-chave: Dendranthema grandiflora, elementos traços, fitodisponibilidade, química de solos, toxicidade, galvanoplastia.

\begin{abstract}
Agricultural use of industrial sludge as a source of $\mathrm{Zn}$ for chrysanthemum cultivation

The use of inorganic industrial sludge as a source of nutrients in growing media is a recent practice. The sludge produced by the zincgalvanic industry has a high concentration of plant nutrients such as $\mathrm{Zn}, \mathrm{Fe}$ and $\mathrm{Ca}$ that, depending on the doses used in soils and growing media, could be toxic to the plants. In the present experiment a commercial organic substrate was used by adding increasing doses of an industrial sludge produced by a zinc-galvanic industry. Doses of industrial sludge $(0.0 ; 0.38 ; 0.75 ; 1.50 ; 3.0 ; 6.0 ; 9.0$ and $12.0 \mathrm{~g} \mathrm{~L}-$ 1 of the growing media) were applied to the chrysanthemum cv. Rage, cultivated in a greenhouse. After 12 weeks of cultivation, the following variables were measured: $\mathrm{pH}$ and electric condutivity of the substrate, $\mathrm{Zn}$ content of the shoot tissue and substrate, height (HGT), dry mass of the shoots (SDM), flowers (FDM) and roots (RDM). The addition of $0.38 \mathrm{~g} \mathrm{~L}-1$ of industrial sludge caused a small increase in HGT, SDM, FDM and RDM. The industrial sludge can supply nutrients to the crop. In doses higher than $3 \mathrm{~g} \mathrm{~L}-1$ occurred accentuated decreasing of shoot production occurred due to an unbalanced nutrition associated with $\mathrm{Zn}$ toxicity symptoms and high electric conductivity.
\end{abstract}

Keywords: Dendranthema grandiflora, trace elements, phytoavailability, soil chemistry, toxicity, galvanoplasty.

\section{(Recebido para publicação em 1 de julho de 2003 e aceito em 1 de junho de 2004)}

$\mathrm{U}^{\mathrm{i}}$ ma vez que resíduos orgânicos e inorgânicos decorrentes de atividades industriais, contituem-se em poluentes ambientais, é de interesse a sua utilização no cultivo de plantas. É prática comum utilizá-los na composição de substratos comerciais, podendo ser considerado um meio efetivo para reciclar materiais. No entanto, a utilização destes resíduos deve estar embasada em conhecimento técnico-científico para evitar danos ao ambiente e principalmente às plantas (Vance e Pierzynski, 2001).

No caso dos resíduos industriais, a existência de elementos químicos metálicos, nutrientes ou não, é preocupante devido à possibilidade de movimentação destes elementos e à contaminação das águas subterrâneas (Yaron et al., 1996) e dos alimentos (Podlesàková et al., 2001). Por isto, Backes e Kämpf (1991) recomendam a utilização de re- síduos que possam conter metais pesados ou agentes infecciosos na produção de plantas ornamentais, diminuindo a possibilidade de intoxicação de homens e animais (Stringheta et al., 1996). Neste caso, existe ainda a necessidade do controle efetivo das concentrações destes elementos, para não haver perigo de contaminação humana ao manipular ou transportar o produto (Ansorena Miner, 1994).

Dentre as principais características dos substratos úteis para a produção de plantas estão os valores de condutividade elétrica (CE) e pH, além da concentração de macro e micronutrientes (Shillo et al. 2002). Assim, a simples presença de elementos essenciais às plantas no lodo industrial, como é o caso do Cálcio (Ca), Ferro (Fe) e Zinco ( $\mathrm{Zn}$ ), podem, dependendo da sua concentração, causar toxicidade às plantas (Ansorena Miner, 1994; Kabata-Pendias e Pendias,1992).
O lodo industrial produzido pela neutralização, com cal hidratada, do resíduo líquido ácido da galvanoplastia, aparentemente, nunca foi utilizado como fonte de nutrientes para o cultivo de flores. No Brasil, este lodo industrial tem sido colocado em aterros sanitários ou lixões e no melhor dos casos, em aterros industriais onde se acumulam sem nenhuma utilidade e elevados custos para as empresas. Ainda, no caso das deposições mal controladas, como lixões, este lodo oferece perigo ao meio ambiente e aos seres vivos que circulam nestes lugares. Além de elevada concentração de Zn e $\mathrm{Fe}$, existem outros elementos químicos, que na dosagem apropriada, podem ser utilizados como fonte de nutrientes para os vegetais.

Em solos ácidos, no cultivo da alface, este lodo alcalino apresentou características de corretivo do solo. No en- 
tanto, sua elevada condutividade elétrica e elevadas concentrações de Fe e Zn determinaram a morte da cultura, por toxidez de $\mathrm{Zn}$ e elevada condutividade elétrica, em doses superiores a $1 \%$ da massa de solo utilizado (Costa, 2001).

A produção de plantas ornamentais é uma atividade promissora na agricultura moderna. O crisântemo (Dendranthema grandiflora) é uma das principais plantas ornamentais produzidas no Brasil. Esta cultura é exigente em nutrientes, especialmente durante a primeira metade do seu ciclo e é considerada por Badino et al. (1999), planta teste assimiladora de $\mathrm{Pb}$ e $\mathrm{Zn}$. O objetivo do presente trabalho foi avaliar a utilização de doses crescentes de lodo industrial de uma indústria de galvanoplastia-zincagem, como fonte de zinco para a cultura do crisântemo.

\section{MATERIAL E MÉTODOS}

Obteve-se o lodo industrial produzido no processo de neutralização, com cal hidratada, do resíduo líquido ácido, do setor de zincagem de uma indústria de galvanização localizada na região metropolitana de Maringá-PR. O lodo industrial produzido no processo de neutralização foi drenado, seco e peneirado a $2 \mathrm{~mm}$. A análise química dos teores totais do lodo sólido, após dissolução total ácida, apresentou elevada concentração de Fe (20,5 $\left.\mathrm{g} \mathrm{kg}^{-1}\right), \mathrm{Zn}(8,6 \mathrm{~g}$ $\left.\mathrm{kg}^{-1}\right)$ e Ca $\left(10,9 \mathrm{~g} \mathrm{~kg}^{-1}\right)$, além do $\mathrm{Pb}(210$ $\left.\mathrm{mg} \mathrm{kg}^{-1}\right)$.

A análise mineralógica do lodo industrial seco por difração de raios-X (dados não apresentados), pelo método do pó (Whitting, 1965), mostrou que a principal forma sólida de $\mathrm{Zn}$ presente no lodo industrial é o mineral Simonkolleita $(\mathrm{Zn5}(\mathrm{OH}) 8 \mathrm{Cl} 2 \cdot(\mathrm{H} 2 \mathrm{O})$, que apresenta alto grau de substituição isomórfica do $\mathrm{Zn}$ pelo $\mathrm{Fe}$, devido às elevadas concentrações de Fe no resíduo líquido ácido original. Além deste mineral, podem ser detectadas concentrações inferiores a 5\% dos óxidos de ferro goethita $(\alpha-\mathrm{FeOOH})$ e lepidocrocita $(\beta-\mathrm{FeOOH})$.

$\mathrm{O}$ experimento foi conduzido em casa de vegetação, onde se cultivou a cv. Rage de crisântemo (Dendranthema grandiflora, Tzevelev) em vasos de $1 \mathrm{~L}$

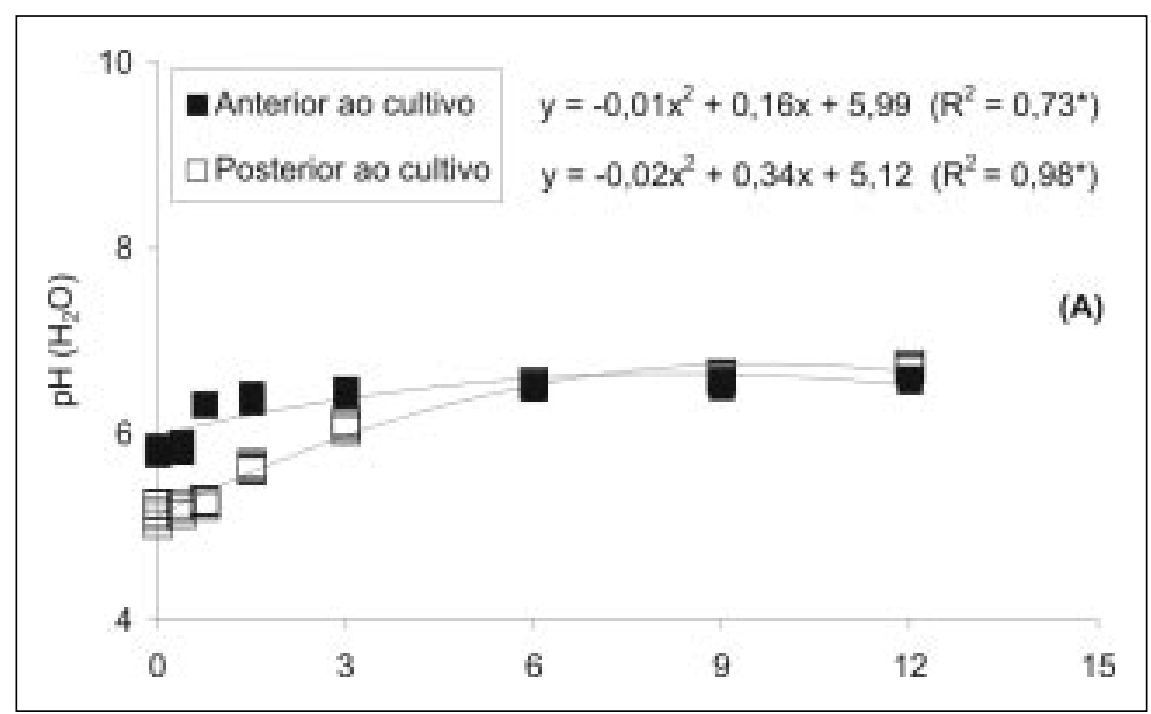

Figura 1. Valores de pH (A) e CE (B) anterior e posterior ao cultivo do crisântemo, em resposta à aplicação do lodo industrial da galvanoplastia-zincagem ao substrato comercial. *Valores de R2 são significativos ao nível de 1\% pelo teste T. Maringá, UEM, 2003.

de volume, com 5 plantas por vaso. Em cada vaso foi adicionado o substrato orgânico comercial Terra do Paraíso®, previamente adubado com doses crescentes do lodo industrial $(0,00 ; 0,38$; 0,$75 ; 1,50 ; 3,00 ; 6,00 ; 9,00$ e $\left.12,00 \mathrm{~g} \mathrm{~L}^{-1}\right)$. O substrato comercial é composto, basicamente, de casca de Pinus compostada, vermiculita expandida e turfa processada.

No plantio foram utilizadas mudas de crisântemos enraizadas, que tiveram suplementação de luz diária de 4 horas durante 3 semanas (Ball, 1991) e suplementação nutricional com $\mathrm{N}, \mathrm{P}$ e $\mathrm{K}$, por meio de regas diárias com soluções nutritivas com $300 \mathrm{mg} \mathrm{L}^{-1}$ de $\mathrm{N} \mathrm{e}$ Ke $100 \mathrm{mg} \mathrm{L}^{-1}$ de $\mathrm{P}$ (Gruszynski, 2001). No preparo do substrato, foi adicionado $1 \mathrm{~g}$ de superfosfato simples por litro de substrato para melhor desenvolvimento inicial das mudas (Gruszynski, 2001). O desponte, corte do terço superior das plantas, foi realizado durante a primeira semana do plantio e 3 dias após foi aplicado o regulador químico de crescimento "B-nine" (daminozide), na dose única de $2,5 \mathrm{~g} \mathrm{~L}^{-1}$. A retirada dos botões florais principais foi realizada na nona semana após o plantio, seguindo os tratos culturais (Gruszynski, 2001).

$\mathrm{O}$ corte e as avaliações do experimento ocorreram na décima segunda semana após o plantio, época em que a maioria das inflorescências encontravase aberta. Procedeu-se à colheita ava- liando-se: porte (ALT), massa seca da parte aérea total (MSPA), das raízes (MSR), e área foliar (AF).

A parte aérea do crisântemo, após seca em estufa, foi moída em moinho de facas de 1,0 mm, digerida por via úmida, utilizando solução nitroperclórica 1:6 (Miyazawa et al., 1999) e determinado, no extrato, o teor de zinco.

O substrato foi caracterizado quanto ao $\mathrm{pH}$ (água) e condutividade elétrica (CE), antes e após o cultivo. Além disso, após a colheita do ensaio, no substrato, também foi determinado o teor de zinco após extração com solução Mehlich $1\left(\mathrm{H}_{2} \mathrm{SO}_{4} 0,025 \mathrm{~N}+\mathrm{HCl}\right.$ $0,05 \mathrm{~N}$ ) e leitura em espectrofotômetro de absorção atômica (Silva et al., 1999). O delineamento experimental utilizado foi de blocos inteiramente casualizados, com 8 tratamentos e 5 repetições. A análise dos dados de regressão foi efetuada através das rotinas ProcReg do programa estatístico SAS (Statistical Analysis System, 1999).

\section{RESULTADOS E DISCUSSÃO}

Os coeficientes de correlação de Pearson (R2) entre as variáveis analisadas e as doses de lodo industrial utilizadas foram todos estatisticamente significativos ao nível de $1 \%$, pelo teste T.

As análises dos dados mostraram um pequeno incremento nos valores de $\mathrm{pH}$ do substrato (Figura 1), que inicialmente 


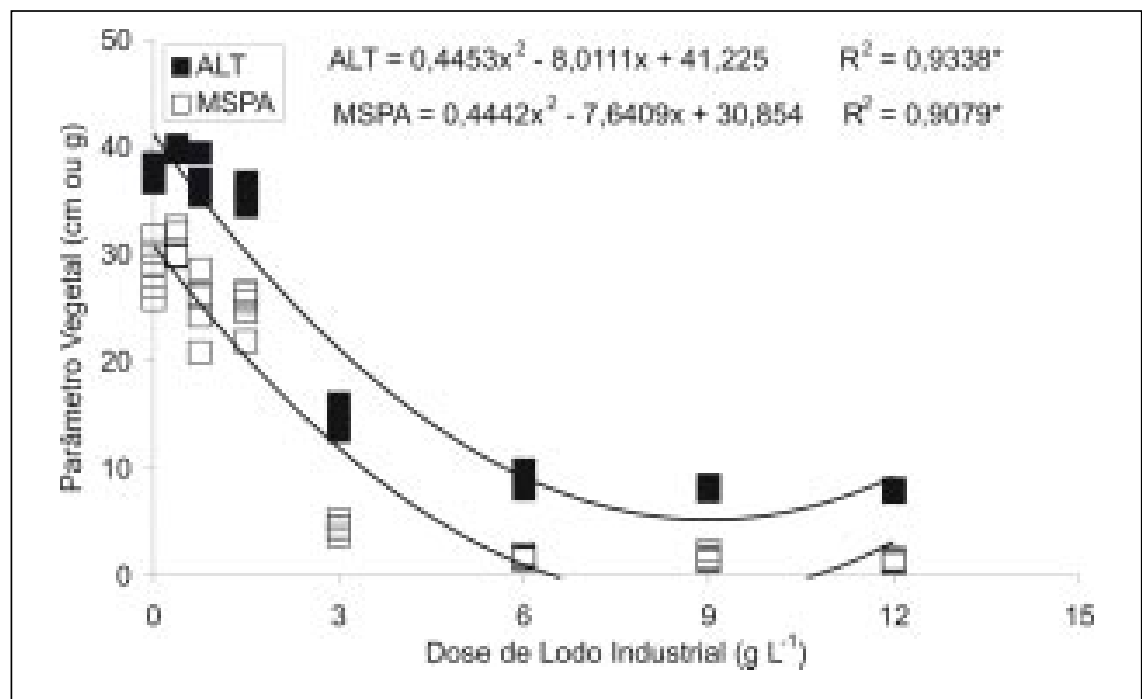

Figura 2. Valores de altura $(\mathrm{cm})$ e massa seca da parte aérea (MSPA) do crisântemo, em resposta a aplicação do lodo industrial da galvanoplastia-zincagem ao substrato comercial, após 12 semanas de cultivo. *Valores de R2 são significativos ao nível de $1 \%$ pelo teste T. Maringá, UEM, 2003.

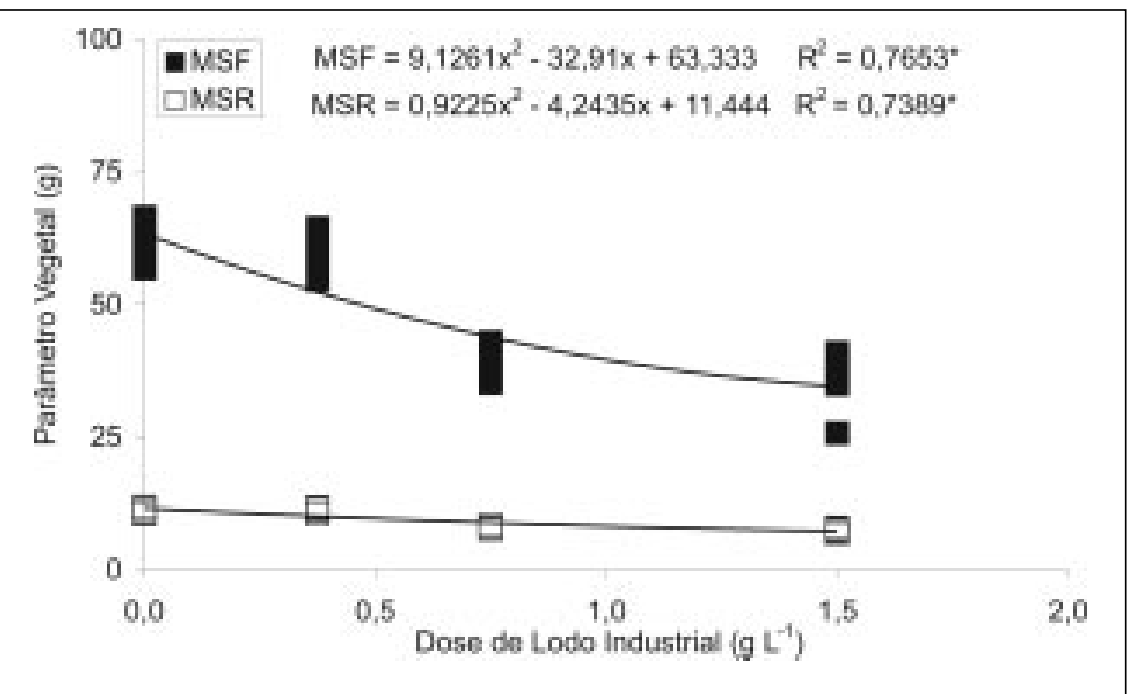

Figura 3. Valores de massa seca de inflorescências (MSF) e massa seca de raízes (MSR) em resposta a aplicação do lodo industrial da galvanoplastia-zincagem ao substrato comercial, após 12 semanas de cultivo. *Valores de R2 são significativos ao nível de $1 \%$ pelo teste T. Maringá, UEM, 2003.

acusa um ganho considerável, tendendo à estabilização nas doses mais elevadas. Os valores de $\mathrm{pH}$ em água (anterior e posterior ao cultivo), diferem nas menores doses, onde o $\mathrm{pH}$ posterior ao cultivo apresenta-se cerca de 0,8 pontos menor em relação ao pH anterior ao cultivo. Este fato resultou na maior produção do crisântemo nas doses menores.

Os valores de CE, com as doses crescentes de lodo industrial, determinaram um forte incremento nos valores de $\mathrm{CE}$ alcançando níveis próximos de $20 \mathrm{dS} \mathrm{m}^{-1}$, antes do cultivo, e decréscimo destes níveis para valores inferiores a $5 \mathrm{dS} \mathrm{m}^{-1}$, após o cultivo (Figura 1). O declínio nos valores de CE é resultado da lixiviação provocada pelas regas diárias e pelo consumo dos sais pelas plantas (Barbosa et al., 1999; Gruszynski, 2001), sendo que as maiores variações ocorreram nas doses mais elevadas. Estas variações demonstram que, embora inicialmente os valores de CE possam ter sido limitantes ao desenvolvimento do crisântemo, com as regas diárias, os valo- res devem ter caído a níveis adequados, não se diferenciando, no final do experimento, entre os tratamentos.

Os resultados da avaliação dos parâmetros vegetais mostraram que houve um incremento na produção de crisântemo comparando-se a testemunha e o tratamento na dose de $0,38 \mathrm{~g} \mathrm{~L}^{-1}$, indicando que o lodo industrial liberou nutrientes para a cultura. No entanto, um forte efeito depressivo na produção de crisântemo foi observado nas doses maiores que $0,38 \mathrm{~g} \mathrm{~L}^{-1}$, sendo que nas doses maiores que $3 \mathrm{~g} \mathrm{~L}^{-1}$ as plantas não completaram seu ciclo de vida.

De outra forma, a dose do lodo industrial requerida para a elevação do $\mathrm{pH}$, próximo de 7,0 é muito superior às necessidades do crisântemo quanto à suplementação de Zn (Costa, et al., 2001), que segundo Gruszynski (2001) é de 20 a $250 \mathrm{mg} \mathrm{L}^{-1}$ e também aos níveis máximos do metal para solos e meios de cultivo, que segundo Ansorena Miner (1994) é de $1500 \mathrm{mg} \mathrm{L}^{-1}$. O lodo industrial contém teores na ordem de 20 $\mathrm{g} \mathrm{kg}^{-1}$ de $\mathrm{Zn}$, portanto, neste caso, as doses de resíduos industriais, quando aplicados na agricultura, devem ser limitadas quanto aos teores de metais presentes no lodo evitando a contaminação do solo e água (Yaron et al.,1996).

Nos tratamentos onde a CE inicial estava acima de $10,0 \mathrm{dS} \cdot \mathrm{m}^{-1}$ o desenvolvimento vegetativo foi baixo. Esta situação foi agravada decorrente de doses excessivas superiores a 3,0 $\mathrm{g} \mathrm{L}^{-1}$, onde a CE inicial encontrava-se acima de $15 \mathrm{dS} \mathrm{m}^{-1}$. Nestes casos, o ciclo vegetativo da espécie não foi concluído. Entretanto, bons resultados foram obtidos nos tratamentos com doses inferiores a $1,5 \mathrm{~g} \mathrm{~L}^{-1} \mathrm{e}$ valores de CE próximas a 5,0 dS m-1. Ansorena Miner (1994) e Shillo et al. (2002) demonstram que existe grande variabilidade nos diferentes níveis de tolerância e resistência à salinidade, entre as diversas espécies de plantas ornamentais. Os níveis iniciais demasiadamente altos (acima de 5,0 dS m $\mathrm{m}^{-1}$ ) de condutividade elétrica, prejudicaram o desenvolvimento de plantas (Shillo et al., 2002). Porém, este efeito depressivo pode estar associado à toxidez de $\mathrm{Zn}$ (Costa et al., 2001). Os altos valores de $\mathrm{CE}$ e toxicidade por $\mathrm{Zn}$ promovem um baixo desenvolvimento vegetativo da 
planta, inclusive do sistema radicular, e ocorrências de cloroses generalizadas (Marschner, 1995). Estes sintomas foram observados nos tratamentos com doses acima de 3,0 $\mathrm{g} \mathrm{L}^{-1}$ e nas curvas de regressão dos parâmetros vegetativos ALT e MSPA (Figura 2) e MSR e MSF (Figura 3).

Por outro lado foi observado o acréscimo no número de inflorescências (NF) (dados não apresentados), mesmo havendo decréscimo da MSF (Figura 3). Isto é, as doses crescentes do lodo sólido determinaram o desequilíbrio nutricional causado pelos níveis tóxicos de $\mathrm{Zn}$, acréscimo de salinidade e do $\mathrm{pH}$ do meio de cultivo que resultaram na maior produção de flores. Resultados semelhantes foram obtidos por Shillo et al. (2002) e Stringheta et al. (1996), sendo que este último trabalhou com crisântemo. Estes autores observaram que além do maior número de inflorescências, as doses maiores do substrato contendo composto de lixo e cascas de arroz carbonizada determinaram atraso no florescimento do crisântemo (Stringheta et al.,1996).

A análise das relações entre o teor de Zn presente na parte aérea em função do teor de Zn no substrato após a colheita do crisântemo mostrou que a cultura apresentou concentrações crescentes (y $=0,6887 x+127,04, \mathrm{R} 2=0,7682 *)$ do elemento até a concentração de $2000 \mathrm{mg}$ $\mathrm{Zn} \mathrm{kg}^{-1}$ de substrato, que foram observadas nas doses inferiores a 3,0 $\mathrm{g} \mathrm{L}^{-1}$ de lodo industrial. Acima destas doses o desenvolvimento vegetativo foi interrompido e houve a morte das plantas. Os altos valores de concentração de Zn observados no tecido vegetal do crisântemo confirmam os dados da literatura (Badino et al., 1999; Gruszynski, 2001), de que esta planta possui elevada capacidade de absorção de zinco. Portanto, ela pode ser cultivada em substratos que apresentem concentrações deste elemento que seriam prejudiciais a outras culturas mais sensíveis.
Os resultados obtidos permitem concluir que embora o lodo industrial seja bastante alcalino, seu uso como condicionador para adequar valores de $\mathrm{pH}$ do substrato é limitado devido à necessidade de respeitar os limites impostos pela CE e teores de metais que podem causar toxicidade às plantas. No entanto, o uso do lodo sólido, quando em doses reduzidas ( $<0,38 \mathrm{~g} \mathrm{~L}^{-1}$ de substrato), mostrou-se eficaz como fonte nutricional, principalmente de $\mathrm{Zn}$, sendo que em doses elevadas, acima de 3,0 $\mathrm{g} \mathrm{L}^{-1}$, provoca toxidez, interrompendo o ciclo da cultura. Além disso, existe a possibilidade do ajuste das doses de lodo sólido aplicadas, com a finalidade de induzir acréscimo no número de inflorescências e retardamento do florescimento, útil a produtores que queiram adequar seus produtos às exigências do mercado.

\section{AGRADECIMENTOS}

À Romagnole Produtos Elétricos Ltda e ao Instituto Euvaldo Lodi pelo financiamento deste projeto de pesquisa.

\section{LITERATURA CITADA}

ANSORENA MINER, J. Substratos, propiedades y caracterización, Bilbao: Mundi Prensa, 1994. 172 p. BACKES, M.A.; KÄMPF, A.N. Substratos à base de composto de lixo urbano para a produção de plantas ornamentais. Pesquisa Agropecuária Brasileira, Brasília, v.26, n.5, p.753-758, 1991.

BADINO, G.; SBERZE, A.; GULMINI, M.; OSTACOLI, G.; ZELANO, V.; MAGRI, G. Biomonitoring method for mountain areas, design aspects and result. Acta Horticulturae, n.457, p.2936, 1999.

BALL, G.J. Ball red book. Chicago: Vic Ball, 1991. 802 p.

BARBOSA, G.J.; MARTINEZ, H.E.P.; KÄMPF

A.N.Acúmulo de macronutrientes em plantas de crisântemo sob cultivo hidropônico em argila expandida para flor-de-corte. Brasília. Pesquisa Agropecuária Brasileira, Brasília, v.34, n.4, p.593-601. 1999.

COSTA, A.C.; CASALI, V.W.D.; RUIZ, H.A.; JORDÃO, C.P.; CECON, P.R. Teor de metais pesados e produção de alface adubada com compostos de lixo urbano. Brasília. Horticultura Brasileira, Brasília, v.19, n.01, p.10-16, 2001.
COSTA, A.C.S. Reciclagem dos resíduos industriais gerados no setor de galvanização da empresa Romagnole Produtos Elétricos Ltda. Mandaguari - Pr. Maringá (s.n.). 2001. 16 p. Relatório de projeto de prestação de serviço.

GRUSZYNSKI, C. Produção comercial de crisântemos: vaso, corte e jardim. Guaíba: Agropecuária, 2001. 116 p.

KABATA-PENDIAS, A.; PENDIAS H. Trace elements in soils and plants. London, CRC Press, 1992. 365 p.

KÄMPF, A.N. Seleção de materiais para uso como substrato. In: KÄMPF, A.N.; FERMINO M.H. (Eds). $1^{\circ}$ Encontro nacional sobre substrato para plantas. Porto Alegre: Gênesis, 2000. p.140-145. MARSCHNER, H. Mineral nutrition of higher plants. 2nd ed. San Diego: Academic Press, 1995. $889 \mathrm{p}$.

MIYASAWA, M.; PAVAN, M, MURAOKA, T; CARMO, C.A.F.S.; MELLO, W.J. Análises químicas de tecido vegetal. In: SILVA, F.C. (org) Manual de análises químicas de solos, plantas e fertilizantes. Brasília:Embrapa, 1999. 171-223.

PODLESÁKOVÁ, E.; NEMECEK, J.; VÁCHA, R. Mobility bioavilability of trace elements in soil. In: ISKANDAR I.K.; KIRKHAM M.B. Trace Elements in Soil: Bioavailability, Flux Tranfer. London: Lewis Publishers, 2001. p.21-41.

RÖBER, R. Substratos Hortícolas: Possibilidades e Limites de sua Composição e Uso: Exemplos da Pesquisa, da Indústria e do Consumo. In: KÄMPF, A.N.; FERMINO M.H.(ed). $1^{\circ}$ Encontro nacional sobre substrato para plantas, Porto Alegre: Gênesis, 2000. p.126-145 .

SAS. STATISTICAL ANALYSIS SYSTEM INSTITUTE. SAS/STAT Procedure guide for personal computer. Version 5, SAS Inst. Cary, NC. 1999.

SHILLO, R; DING, M.; PASTERNAK D.; ZACCAI, M. Cultivation of cut flower and bulb species with saline water. Scientia Horticulture, v.92, p.41-54, 2002.

SILVA, F.C. Análises químicas para avaliação da fertilidade do solo. In: Silva, F.C. (org.) Manual de análise química de solos, plantas e fertilizantes, Brasília: EMBRAPA, 1999. P.75-166

STRINGHETA, A.C.O.; FONTES, L.E.F.; LOPES, L.C.; CARDOSO, A.A. Crescimento de crisântemo em substrato contendo composto de lixo urbano e cascas de arroz carbonizada. Pesquisa Agropecuária, Brasileira, Brasília, v.31, n.11, p.795-802, 1996.

VANCE G.F.; PIERZYNSKI G.M. Bioavailability and fate of trace elements in long-term residual amended soil studies. In ISKANDAR I.K.; KIRKHAM M.B. Trace Elements in Soil: Bioavailability, Flux Tranfer. London. Lewis Publishers, 2001. p.3-19.

YARON, B.; CALVET, R.; PROST, R. Soil Pollution Process and Dynamics. Springer - Verlag Berlin Heidelberg, 1996. 313 p. 